\title{
A Computational Study on Tri and Tetraazaanthracenes
}

\author{
Ahmet KÖLE and Selçuk GÜMÜŞ* \\ Van Yuzuncu Yil University, Faculty of Science, Department of Chemistry, 65080, Van, Turkey \\ E-mail: gumuss@gmail.com
}

\begin{abstract}
Tri and tetraazaanthracene derivatives have been considered theoretically to obtain information about their stabilities and aromaticities. The expected decrease of aromaticity of parent anthracene by tri or tetraaza substitution has been compensated by substitution of one of the hydrogens of the system by an electronegative group. The position of the substituent has been proved to be strongly effective on the aromaticity of the structure such that, the aromaticity is enhanced when the susbtituent is closer to the aza points.
\end{abstract}

Keywords: Aromaticity; triazaanthracenes; tetraazaanthracenes; NICS

\section{Introduction}

Aromatic compounds such as benzene, naphthalene, and anthracene play very important roles in organic chemistry. Anthracene is a solid polycyclic aromatic hydrocarbon consisting of three fused benzene rings. It is used in the production of the red dye alizarin and other dyes. Anthracene is colorless but exhibits blue (400-500 nm peak) fluorescence under ultraviolet light [1].

Photodimerization of anthracene occurs under UV radiation. Moreover, anthracene gives reduction and oxidation reactions which yield 9,10-dihydroanthracene and anthraquinone, respectively. The ease to preserve the two separate aromatic benzene ring on each side leads anthracene to behave as a diene through 9 and 10 positions [2,3].

Aromaticity still continues to be an actively investigated area of chemistry. The simplest criterion for aromatic compounds is that they possess cyclic conjugated $\pi$-systems containing the proper number of $\Pi$-electrons (i.e., the Hückel rule). While this criterion is sufficiently strong to predict the aromaticity of a host of neutral and charged ring systems, it is not always a good indicator of aromaticity for more complex systems (as in the present case).

Aromaticity is expressed by a combination of properties in cyclic delocalized systems. In general, aromaticity is discussed in terms of energetic, structural and magnetic criteria [4-9]. In 1996, Schleyer has introduced a simple and efficient probe for aromaticity: Nucleus-independent chemical shift (NICS) [10], which is the computed value of the negative magnetic shielding at some selected point in space, generally, at a ring or cage center. Negative NICS values denote aromaticity ( -11.5 for benzene, -11.4 for naphthalene) and positive NICS values denote antiaromaticity (28.8 for cyclobutadiene) while small NICS values indicate non aromaticity ( -2.1 for cyclohexane, -1.1 for adamantane) [10]. NICS may be a useful indicator of aromaticity that usually correlates well with the other energetic, structural, and magnetic criteria for aromaticity [11-14]. Resonance energies and magnetic susceptibilities are measures of the overall aromaticity of a polycycle, but do not provide information about the individual rings. NICS is an effective probe for local aromaticity of individual rings of polycyclic systems.

The aromatic character of several organic compounds including anthracene has been investigated theoretically by Schleyer and co-workers [10]. They applied B3LYP/6-31G(d) method for the computation of NICS data and obtained -8.2 and -13.3 for outer and inner ring of anthracene, respectively.

The present article reveals the results of the theoretical investigation on the effect centric diaza substitution on the aromaticity of parent anthracene. Moreover, the effect of types and positions of the susbtituents on tri and tetraazacompounds has been investigated by the applications of NICS and electronic energy calculations. 


\section{Method of Calculation}

The initial geometry optimizations of all the structures leading to energy minima were achieved by using semi-empirical PM3 self-consistent field molecular orbital (SCF MO) method [15, 16] at the restricted level [17]. Then, geometry optimizations were achieved within the framework of density functional theory (DFT, B3LYP) [18, 19] at the level of $6-31 \mathrm{G}(\mathrm{d}, \mathrm{p})[17]$ without any symmetry constrains. The exchange term of B3LYP consists of hybrid Hartree-Fock and local spin density (LSD) exchange functions with Becke's gradient correlation to LSD exchange [20]. The correlation term of B3LYP consists of the Vosko, Wilk, Nusair (VWN3) local correlation functional [21] and Lee, Yang, Parr (LYP) correlation correction functional [22]. The BLYP method gives a better improvement over the SCF-HF results. Its predictions are in qualitative agreement with experiment [23-25].

The normal mode analysis for the structures yielded no imaginary frequencies for the $3 N-6$ vibrational degrees of freedom, where $N$ is the number of atoms in the system. This indicates that the optimized structure of each molecule corresponds to at least a local minimum on the potential energy surface. Absolute NMR shielding values [26] were calculated using the Gauge-Independent Atomic Orbital (GIAO) method [27] with the restricted closed shell formalism employing 6-31G(d,p) basis set over B3LYP/6-31G(d,p) optimized geometries.

NICS data were obtained by the computation of absolute NMR shielding at the ring centers, NICS(0). The geometry optimizations and NICS calculations of the present systems were performed by using the Gaussian 09 package program [28].

\section{Results and Discussion}

Substituted phenazine cores are important biologically active motifs, and are usually found in natural products, dyestuffs, pesticides, and antibiotics. A majority of the naturally occurring phenazines are produced by bacteria from diverse genera including Pseudomonas, Pelagiobacter, Vibrio, and Streptomyces species [29].

The effect of centric perturbation of an heteroatom to the central ring, and/or substitution of an heteroatom or heterogroup with the hydrogens of well-known aromatic compounds have always found application in both theoretical and experimental studies. In the present article, all possible triazaanthracene and tetraazaanthracene derivatives and their susbtituted $\left(\mathbf{N O}_{2}\right)$ counterparts have been investigated theoretically by the application of B3LYP/6-31G(d,p) level of theory in order to judge their stabilities and aromaticities.

The mono and/or dicentric perturbation on positions of ring fusions are excluded since non-aromatic systems are obtained in those cases. The molecules were named according to the positions of the nitrogens on the system from A-1-2-3 to A-2-3-9 for triazaanthracene and A-1-2-3-4 to A-1-3-5-10 (see Figure 1). The structure $\mathbf{1}$ is used to show the numbering of the atoms to indicate the position of the heteroatom substitution. 


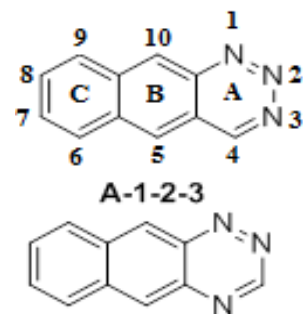

A-1-2-4<smiles>c1cnc2cc3ccnnc3cc2c1</smiles>

A-1-2-5<smiles>c1cc2cc3nnccc3cc2cn1</smiles>

A-1-2-6<smiles>c1cc2cc3ccnnc3cc2cn1</smiles>

A-1-2-7<smiles>c1cnc2cc3nnccc3cc2c1</smiles>

A-1-2-8<smiles>c1ccc2nc3nnccc3cc2c1</smiles>

A-1-2-9<smiles>c1ccc2nc3ccnnc3cc2c1</smiles>

A-1-2-10<smiles>c1cnc2cc3ncncc3nc2c1</smiles>

A-1-3-10<smiles>c1cnc2cc3cncnc3cc2c1</smiles>

A-1-3-5<smiles>c1cc2cc3ncncc3cc2cn1</smiles>

A-1-3-6<smiles>c1cc2cc3cncnc3cc2cn1</smiles>

A-1-3-7<smiles>c1cnc2cc3ncncc3cc2c1</smiles>

A-1-3-8<smiles>c1ccc2nc3ncncc3cc2c1</smiles>

A-1-3-9<smiles>c1ccc2nc3cncnc3cc2c1</smiles>

A-1-3-10<smiles>c1cnc2cc3nccnc3cc2c1</smiles>

A-1-4-5<smiles>c1cc2cc3nccnc3cc2cn1</smiles>

A-1-4-6<smiles>c1ccc2nc3nccnc3cc2c1</smiles>

A-1-4-9<smiles>c1cnc2cc3cnncc3cc2c1</smiles>

A-2-3-5<smiles>c1cc2cc3cnncc3cc2cn1</smiles>

A-2-3-6<smiles>c1ccc2nc3cnncc3cc2c1</smiles>

A-2-3-10<smiles>c1ccc2cc3nnnnc3cc2c1</smiles>

A-1-2-3-4<smiles>c1cnc2cc3cnnnc3cc2c1</smiles>

A-1-2-3-5<smiles>c1cc2cc3nnncc3cc2cn1</smiles>

A-1-2-3-6<smiles>c1cc2cc3nnncc3cc2cn1</smiles>

A-1-2-3-7<smiles>c1cnc2cc3nnncc3cc2c1</smiles>

A-1-2-3-8<smiles>c1ccc2nc3nnncc3cc2c1</smiles>

A-1-2-3-9<smiles>c1cnc2cc3nnncc3nc2c1</smiles>

A-1-2-3-10<smiles>c1cnc2cc3ncnnc3cc2c1</smiles>

A-1-2-4-5<smiles>c1cc2cc3nncnc3cc2cn1</smiles>

A-1-2-4-6<smiles>c1cc2cc3ncnnc3cc2cn1</smiles>

A-1-2-4-7<smiles>c1cnc2cc3nncnc3cc2c1</smiles>

A-1-2-4-8<smiles>c1ccc2nc3nncnc3cc2c1</smiles>

A-1-2-4-9<smiles>c1ccc2nc3ncnnc3cc2c1</smiles>

A-1-2-4-10<smiles>c1cc2cc3cnncc3cc2nn1</smiles>

A-1-2-5-6<smiles>c1ncc2cc3cnncc3cc2n1</smiles>

A-1-2-5-7<smiles>c1cnc2cc3cnncc3cc2n1</smiles>

A-1-2-5-8<smiles>c1cnc2cc3cnncc3nc2c1</smiles>

A-1-2-5-9<smiles>c1cnc2nc3cnncc3cc2c1</smiles>

A-1-2-5-10<smiles>c1ncc2cc3ncncc3cc2n1</smiles>

A-1-3-5-7<smiles>c1ncc2cc3nccnc3cc2n1</smiles>

A-1-3-5-8<smiles>c1cnc2cc3cncnc3nc2c1</smiles>

A-1-3-5-9<smiles>c1cnc2nc3cncnc3cc2c1</smiles>

A-1-3-5-10<smiles>c1cc2cc3ncncc3cc2nn1</smiles>

A-1-3-5-6

Figure 1. Possible tri and tetraaza derivatives of anthracene. The numbering of the points and the naming of the rings have been shown on compound A-1-2-3

\subsection{Energetics}

The zero point corrected total electronic energies of the present systems have been obtained by the aforementioned method. The total energies (in a.u.) and corresponding relative energies (in $\mathrm{kJ} / \mathrm{mol}$ ) of the systems are given in Table 1 and Figure 2 shows the calculated relative electronic energies of the unsubstituted tri and tetraazaanthracene derivatives. The lowest energy compounds have been found to 
be A-1-3-10 for triazaanthracene (blue curve) and A-1-3-5-7 for tetraazaanthracene (green curve) series and the graph has been drawn accordingly.

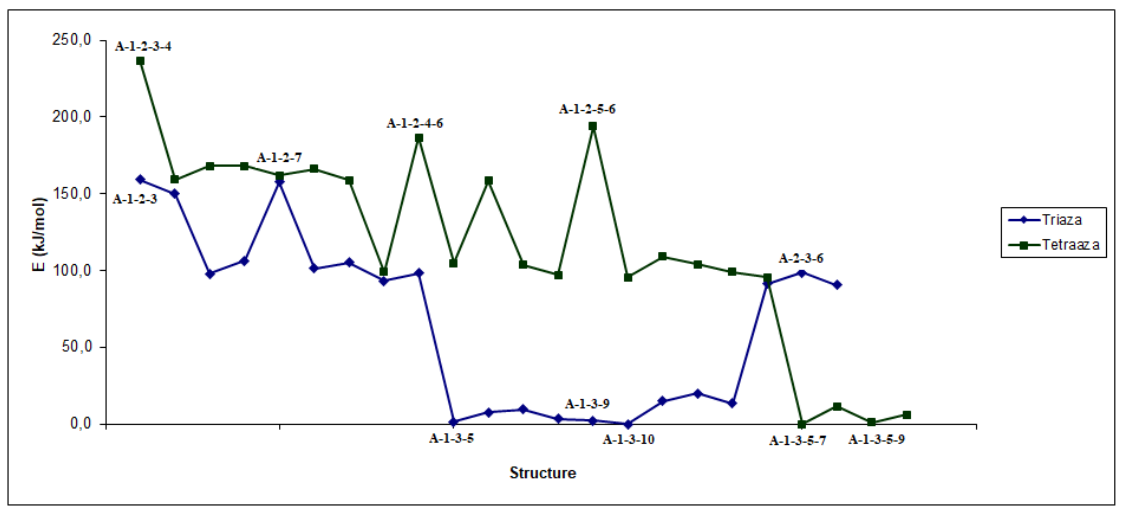

Figure 2. Relative energies of compounds of the two series.

The drastic instability A-1-2-3, A-1-2-7 and A-2-3-6 over the others can be attributed to vicinal positioning of the two nitrogen atoms, which distrubs the aromaticity of the related system much more than the other substitutions. The same observation is also valid for the tetra series since A-1-2-3-4, A1-2-4-6, A-1-2-5-6 are the least stable structures where nitrogens have been located much more closer.

Table 1. Total energies (a.u.) and corresponding relative energies $(\mathrm{kJ} / \mathrm{mol})$ of the two series

\begin{tabular}{|c|c|c|c|c|c|}
\hline Structure & Total Energy & Relative Energy & Structure & Total Energy & Relative Energy \\
\hline$A-1-2-3$ & -587.6135671 & 159.3 & A-1-2-3-4 & -603.6185451 & 236.6 \\
\hline A-1-2-4 & -587.6172525 & 150.0 & $A-1-2-3-5$ & -603.6492033 & 159.2 \\
\hline A-1-2-5 & -587.6378970 & 97.8 & A-1-2-3-6 & -603.6457389 & 167.9 \\
\hline A-1-2-6 & -587.6345870 & 106.2 & $A-1-2-3-7$ & -603.6457630 & 167.9 \\
\hline A-1-2-7 & -587.6141898 & 157.7 & A-1-2-3-8 & -603.6481847 & 161.7 \\
\hline A-1-2-8 & -587.6365824 & 101.2 & A-1-2-3-9 & -603.6464899 & 166.0 \\
\hline A-1-2-9 & -587.6349982 & 105.2 & $A-1-2-3-10$ & -603.6492945 & 158.9 \\
\hline$A-1-2-10$ & -587.6397171 & 93.2 & A-1-2-4-5 & -603.6731205 & 98.8 \\
\hline A-1-3-4 & -587.6378006 & 98.1 & A-1-2-4-6 & -603.6383514 & 186.6 \\
\hline A-1-3-5 & -587.6760826 & 1.4 & A-1-2-4-7 & -603.6707355 & 104.8 \\
\hline A-1-3-6 & -587.6735872 & 7.7 & A-1-2-4-8 & -603.6494935 & 158.4 \\
\hline A-1-3-7 & -587.6728889 & 9.5 & A-1-2-4-9 & -603.6712574 & 103.5 \\
\hline A-1-3-8 & -587.6753048 & 3.4 & A-1-2-4-10 & -603.6738421 & 96.9 \\
\hline A-1-3-9 & -587.6757886 & 2.1 & A-1-2-5-6 & -603.6354070 & 194.0 \\
\hline A-1-3-10 & -587.6766381 & 0.0 & A-1-2-5-7 & -603.6744140 & 95.5 \\
\hline A-1-4-5 & -587.6707481 & 14.9 & A-1-2-5-8 & -603.6691281 & 108.8 \\
\hline A-1-4-6 & -587.6687525 & 19.9 & A-1-2-5-9 & -603.6711181 & 103.8 \\
\hline A-1-4-9 & -587.6713482 & 13.4 & A-1-2-5-10 & -603.6730714 & 98.9 \\
\hline A-2-3-5 & -587.6405147 & 91.2 & A-1-3-5-6 & -603.6744140 & 95.5 \\
\hline A-2-3-6 & -587.6376303 & 98.5 & A-1-3-5-7 & -603.7122271 & 0.0 \\
\hline \multirow[t]{3}{*}{$A-2-3-9$} & -587.6408745 & 90.3 & A-1-3-5-8 & -603.7076979 & 11.4 \\
\hline & & & $A-1-3-5-9$ & -603.7117743 & 1.1 \\
\hline & & & $A-1-3-5-10$ & -603.7098677 & 6.0 \\
\hline
\end{tabular}

\section{$3.2 \quad$ NICS}

Stanger describes major paradigms in the field of aromaticity, and emphasizes the contradictions and paradoxes between these paradigms, and between different measures of aromaticity [30]. 
The delocalization of certain number of $\pi$-electrons freely in a ring accounts for the aromaticity in that ring which results in better stability. NICS is a measure aromaticity related to the magnetic properties of the ring under consideration. The most well-known aromatic compound is benzene where there exist a perfect delocalization of six $\pi$-electrons. Therefore, central substitution of an heteroatom decreases the aromaticity of the system to some extent due to the electronegativity difference between carbon and other atoms. The aromaticity of that ring even decreases more with the substitution of a second heteroatom like in the present case. The NICS data for the parent anthracene, tri and tetraaza substituted anthracene derivatives are given in Table 2.

Table 2. NICS (ppm) data for the present systems

\begin{tabular}{lccclcccc}
\hline \multirow{2}{*}{ Structure } & \multicolumn{3}{c}{ NICS } & & & \multicolumn{3}{c}{ NICS } \\
\cline { 2 - 3 } & A & B & C & & & A & B & C \\
\hline A-1-2-3 & -3.66 & -11.83 & -7.85 & A-1-2-3-4 & -2.29 & -12.61 & -7.94 \\
A-1-2-4 & -1.49 & -8.29 & -7.54 & A-1-2-3-5 & -3.87 & -12.04 & -6.51 \\
A-1-2-5 & -6.02 & -11.73 & -5.74 & A-1-2-3-6 & -3.74 & -11.85 & -6.77 \\
A-1-2-6 & -5.74 & -11.72 & -6.30 & A-1-2-3-7 & -3.67 & -11.78 & -6.79 \\
A-1-2-7 & -5.81 & -11.57 & -6.20 & A-1-2-3-8 & -3.78 & -11.98 & -6.68 \\
A-1-2-8 & -5.84 & -11.69 & -6.22 & A-1-2-3-9 & -3.88 & -11.06 & -7.60 \\
A-1-2-9 & -5.91 & -11.05 & -7.06 & A-1-2-3-10 & -3.99 & -10.88 & -7.69 \\
A-1-2-10 & -7.27 & -10.45 & -6.10 & A-1-2-4-5 & -6.02 & -12.35 & -4.58 \\
A-1-3-4 & -4.50 & -12.12 & -7.37 & A-1-2-4-6 & -4.06 & -12.75 & -6.75 \\
A-1-3-5 & -5.58 & -11.65 & -6.36 & A-1-2-4-7 & -6.31 & -12.04 & -4.46 \\
A-1-3-6 & -5.31 & -11.36 & -6.41 & A-1-2-4-8 & -3.48 & -14.30 & -5.63 \\
A-1-3-7 & -5.58 & -11.60 & -6.54 & A-1-2-4-9 & -4.61 & -11.62 & -7.06 \\
A-1-3-8 & -5.57 & -11.62 & -6.35 & A-1-2-4-10 & -7.05 & -11.02 & -4.87 \\
A-1-3-9 & -5.67 & -10.37 & -7.38 & A-1-2-5-6 & -5.53 & -12.26 & -5.50 \\
A-1-3-10 & -5.55 & -10.70 & -7.49 & A-1-2-5-7 & -5.15 & -11.80 & -5.75 \\
A-1-4-5 & -6.40 & -11.78 & -4.94 & A-1-2-5-8 & -5.87 & -12.05 & -4.75 \\
A-1-4-6 & -5.03 & -11.64 & -6.58 & A-1-2-5-9 & -5.93 & -11.14 & -5.89 \\
A-1-4-9 & -5.19 & -10.86 & -7.52 & A-1-2-5-10 & -6.17 & -10.74 & -6.03 \\
A-2-3-5 & -6.63 & -11.63 & -4.45 & A-1-3-5-6 & -5.15 & -11.80 & -5.75 \\
A-2-3-6 & -4.41 & -11.55 & -6.74 & A-1-3-5-7 & -5.61 & -11.85 & -5.62 \\
A-2-3-9 & -4.32 & -10.45 & -7.77 & A-1-3-5-8 & -5.50 & -11.89 & -5.11 \\
& & & & A-1-3-5-9 & -5.84 & -10.52 & -6.29 \\
& & & & A-1-3-5-10 & -6.53 & -11.02 & -5.58 \\
\hline
\end{tabular}

The data show what was being expected. Centric subtitution of nitrogen decreases the aromaticity of that ring. The aromaticity of the A ring of the triazasubstituted rings decreased to $-1.49 \mathrm{ppm}$ for A-12-4 (level of non-aromaticity) and $\mathbf{- 3 . 6 6} \mathrm{ppm}$ for A-1-2-3 derivative. Moreover, a NICS data of $\mathbf{- 2 . 2 9}$ ppm have been obtained for A-1-2-3-4. While, the aromaticity of the central curcuit of the substituted anthracenes is around $-11-12 \mathrm{ppm}$.

However, the lost aromaticity can be gained back by the substitution of hydrogens by an electronegative atom or group. The strong electronegative power of the substituent can pull the electrons located on the heteroatom on the central ring back into the ring to enhance the aromaticity. In our case, the effect of substitution of strongly electron withdrawing $\mathbf{N O}_{2}$ group on the aromaticity of the system has been investigated by calculating the NICS data at the ring centers (NICS $(0))$.

According to the results of NICS calculations of substituted tri and tetraazaanthracene derivatives, it is clear that the system becomes more aromatic by the susbtitution which confirms the explanation above. The NICS data for the A rings of triple aza containing rings (A-1-2-3 and A-1-2-4 ) are computed to be smaller relative to the mono or diaza containing rings [31]. Therefore, the substitution has been accepted to be more effective on the improvement of the aromaticity in the former cases. The 
A ring of the unsubstituted compounds A-1-2-3 and A-1-2-4 have NICS values of -3.66 and -1.49 $\mathrm{ppm}$, respectively. The lost aromaticities of these systems have been enhanced to -6.32 and $-6.44 \mathrm{ppm}$ upon substitution of $\mathrm{NO}_{2}$, respectively. Going through the NICS data for different positions of the substituents, when substitutin is closer the aza points of the rings, the structure becomes more aromatic. Inversely, NICS of the systems gets smaller (in absolute value) while the electronegative group susbtituted farther (Figure 3).

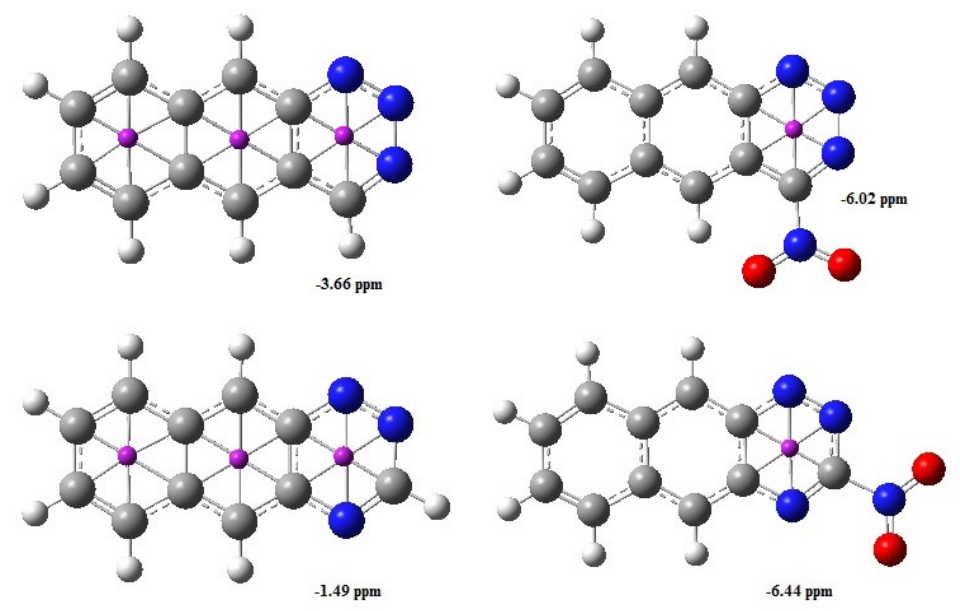

Figure 3. Effect of $\mathrm{NO}_{2}$ substitutin on the aromaticity of the compounds.

\section{Conclusion}

All possible tri and tetraazaanthracene derivatives have been considered theoretically at the level of density functional theory calculations with B3LYP/6-31G(d,p) method. As a result, the vicinal aza substitution has not been favored by the system. Secondly, the aromaticities depend on the position of the substituent. The position of the substituent has been investigated. The system becomes more aromatic (possess greater negative NICS data) when the electronegative atoms or groups are closer to the centrically substituted nitrogen atoms.

Acknowledgement. We are grateful to the Presidency of Scientific Research Projects of Van Yuzuncu Yil University (BAP) for the grant (No. FYL-2018-6746).

\section{References}

1. Stevenson, L. S. The Fluorescence of Anthracene. (New York: Nabu Press, 2012).

2. Bernas, A., D. Leonardi, and M. Renaud. Photochem. Photbiol. 5 (1966): 721.

3. Chandross, E. A. and J. J. Ferguson. Chem. Phys. 45 (1966): 3564.

4. Minkin, V. I., M. N. Glukhovtsev, and B. Y. Simkin. Aromaticity and Antiaromaticity:Electronic and Structural Aspects. (New York: Wiley, 1994).

5. Schleyer, P. R. and H. Jiao. Pure Appl. Chem. 68 (1996): 209.

6. Glukhovtsev, M. N. J. Chem. Educ. 74 (1997): 132.

7. Krygowski, T. M.,M. K. Cyranski, Z. Czarnocki, G. Hafelinger, and A. R. Katritzky.Tetrahedron 56 (2000): 1783.

8. Schleyer, P. R. Chem. Rev. 101 (2001): 1115.

9. Cyranski, M. K., T. M. Krygowski, A. R. Katritzky, and P. R. Schleyer. J. Org. Chem. 67 (2002): 1333.

10. Schleyer, P. R., C. Maerker, A. Dransfeld, H. Jiao, and N. J. R. E. Hommes, J. Amer. Chem. Soc. 118 (1996): 6317 .

11. Jiao, H. and P. R. Schleyer. J. Phys. Org. Chem. 11 (1998): 655.

12. Schleyer, P. R., B. Kiran, D. V. Simion, and T. S. Sorensen. J. Amer. Chem. Soc. 122 (2000): 510.

13. Quinonero, D., C. Garau, A. Frontera, P. Ballaster, A. Costa, and P. M. Deya. Chem. Eur. J. 8 (2002): 433. 
14. Patchkovskii, S. and W. Thiel. J. Mol. Model 6 (2002): 67.

15. Stewart, J. J. P. J. Comput. Chem. 10 (1989): 209.

16. Stewart, J. J. P. J. Comput. Chem. 10 (1989): 221.

17. Leach, A. R. Molecular Modelling (Essex: Longman, 1997).

18. Kohn, W. and L. J. Sham. Phys. Rev. 140 (1965): 1133.

19. Parr, R. G. and W. Yang. Density Functional Theory of Atoms and Molecules (London: Oxford University Press, 1989).

20. Becke, A. D. Phys. Rev. A 38 (1988): 3098.

21. Vosko, S. H., L. Vilk, and M. Nusair. Can. J. Phys. 58 (1980): 1200.

22. Lee, C., W. Yang, and R. G. Parr. Phys. Rev. B 37 (1988): 785.

23. Scuseria, G. E. J. Chem. Phys. 97 (1992): 7528.

24. Sosa, C. and C. Lee. J. Chem. Phys. 98 (1993): 8004.

25. Wilson, P. J., R. D. Amos, and N. C. Handy. Phys. Chem. Chem. Phys. 2 (2000): 187.

26. Pulay, P., J. F. Hinton, and K. Wolinski. "Nuclear Magnetic Shieldings And Molecular Structure." In Ed. J. A. Tossel, NATO ASI Series C, vol. 386 (Netherlands: Kluwer, 1993) 243-262.

27. Hehre,W. J., L. Radom, P. R. Schleyer, and J. A. Pople. Ab Initio Molecular Orbital Theory (New York: Wiley, 1986).

28. Frisch, M. J.,G.W. Trucks, H. B. Schlegel,G.E. Scuseria, M. A. Robb, J.R.Cheeseman, J. A. Montgomery Jr., T. Vreven, K. N. Kudin, J. C. Burant, J. M. Millam, S. S. Iyengar, J. Tomasi, V. Barone, B. Mennucci, M. Cossi, G. Scalmani, N. Rega, G. A. Petersson, H. Nakatsuji, M. Hada, M. Ehara, K. Toyota, R. Fukuda, J. Hasegawa, M. Ishida, T. Nakajima, Y. Honda, O. Kitao, H. Nakai, M. Klene, X. Li, J.E. Knox, H. P. Hratchian, J. B. Cross, C. Adamo, J. Jaramillo, R. Gomperts, R. E. Stratmann, O. Yazyev, A. J. Austin, R. Cammi, C. Pomelli, J. W. Ochterski, P. Y. Ayala, K. Morokuma, G.A. Voth, P. Salvador, J. J. Dannenberg, V. G. Zakrzewski, S. Dapprich, A. D. Daniels, M. C. Strain, O. Farkas, D. K. Malick, A. D. Rabuck, K. Raghavachari, J. B. Foresman, J. V. Ortiz, Q. Cui, A. G. Baboul, S. Clifford, J. Cioslowski, B. B. Stefanov, G. Liu, A. Liashenko, P. Piskorz, I. Komaromi, R. L. Martin, D. J. Fox, T. Keith, M. A. Al-Laham, C. Y. Peng, A. Nanayakkara, M. Challacombe, P. M. W. Gill, B. Johnson, W. Chen, M. W. Wong, C. Gonzalez, J. A. Pople. (Wallingford, CT: Gaussian Inc., 2004).

29. Yu, L., X. Zhou, D. Wu, and H. Xiang. J. Organometall. Chem. 705 (2012): 75.

30. Stanger A. Chem. Commun. (2009): 1939.

31. Gümüş, S., Akbay, M. Polycyclic Arom. Comp. 33 (2013) 519. 